\title{
Potentialities of Vis-NIR spectroradiometry for mapping traffic emissions in urban environments
}

\author{
R. Salzano ${ }^{1}$, R. Salvatori ${ }^{1}$, M. Angelone ${ }^{2}$ \& R. Casacchia ${ }^{1}$ \\ ${ }^{I}$ CNR, Istituto per lo studio dell'Inquinamento Atmosferico, Italy \\ ${ }^{2}$ ENEA, C.R. Casaccia, PROT-CHIM, Italy
}

\begin{abstract}
Traffic emissions introduce in urban environments low-reflectance matter, which affects the optical properties of atmosphere and consequently of soils, where particulate matter is accumulated. Radiometric techniques, focused on the 350$2500 \mathrm{~nm}$ wavelength range, were applied to investigate the alteration of optical properties of soils in urban environments. An integration between radiometric data and geochemical analyses was made to estimate the relationship occurring between optical properties of soils and their heavy metals content, which may trace traffic pollution. Soil samples were sampled in two study areas and treated to perform geochemical analyses and spectroradiometric acquisitions. An experimental analytical protocol was developed to study the optical properties of soils. The optical properties of urban soils are influenced by the deposition of carbonaceous particles and by the interaction between soil phases and traffic emissions. Results showed that the integrated approach of radiometric and geochemical investigations is a valid tool for monitoring traffic emissions in urban environments.
\end{abstract}

Keywords: soil geochemistry, spectral analysis, urban pollution, radiometry.

\section{Introduction}

Monitoring of pollution in urban environments is one of the major challenges for the scientific community. The urban environment is a complex, heterogeneous system, being characterized by different climatic, urban and geological features. The investigation of each of these characteristics can be performed by a great 
variety of techniques and methods. Although these tools are nowadays very advanced and allow scientists to thoroughly investigate each task, a complete survey about the anthropic impact on the urban system requires a considerable amount of time and resources.

Soils are exposed towards contaminants and can record the atmospheric pollution. The pedosphere is conventionally investigated using geochemical techniques (Fergusson [5]), even though these methods are expensive and time consuming. Geochemical analyses are usually performed on major elements (i.e. $\mathrm{Fe}, \mathrm{Al}, \mathrm{Mn}$ ), which are mainly associated with the mineral phases, and to heavy metals $(\mathrm{Pb}, \mathrm{Ba}, \mathrm{Zn}, \mathrm{Cu}$ and $\mathrm{Cd})$, that are a primary constituent of most vehicular parts and fuels (Hamilton and Harrison [7]). These metals are already present in the soil parent material and can migrate through the soil profile as a result of pedogenesis. The anthropic fallout can be fixed by soils, adsorbed by organic matter, clay minerals and iron-manganese oxy-hydroxide.

Reflective spectroscopy, which is based on the interaction between electromagnetic radiation and matter, is possibly an alternative method to contribute the monitoring of soil pollution. This discipline is a branch of radiometry and studies light, as a function of wavelength, which has been reflected or dispersed by a solid, a liquid or a gas. When photons intercept a solid surface, some of them are reflected, some are transmitted and others are absorbed. The reflected scattered photons strike other grains and are dispersed far away from the surface to be detected and measured. Minerals, due to several processes, absorb photons. The variety of absorption phenomena and their relationship with specific wavelength provides information about the mineral chemistry (Leone and Sommer [8]; Palacios-Orueta and Ustin [9]) and different soil properties (Galvao et al. [6]; Undelhoven et al. [11]). In this context several studies are focused on the detection of the relationship between reflectance and chemical parameters. This technique was tested mainly in large rural areas, where mineralogical and pedological properties are strongly different. Most of these applications are, in fact, dedicated to agricultural purposes and to the land management. These objectives are not accomplishable in an urban context, because soil differences are more subtle, thus making soil identification more difficult. The hypothesis which support the using of reflective spectroscopy in urban environments is that anthropic emissions introduce dark particulate matter which, falling out on the ground and interacting with soils, can alter optical properties of soils.

\section{Study area}

Rome is an ideal site to investigate soil contamination. It is the sixth largest European city (City Majors [2]) with about 2,700,000 residents widespread over $360 \mathrm{~km}^{2}$ wide district; about $50 \%$ of this area is heavily urbanized. In this region and in the surrounding area, large industrial or thermo-electric plants are absent; thus the major source of atmospheric pollution is vehicular traffic, estimated to exceed more than 2,000,000 vehicles, circulating daily all over the urban road pattern. 


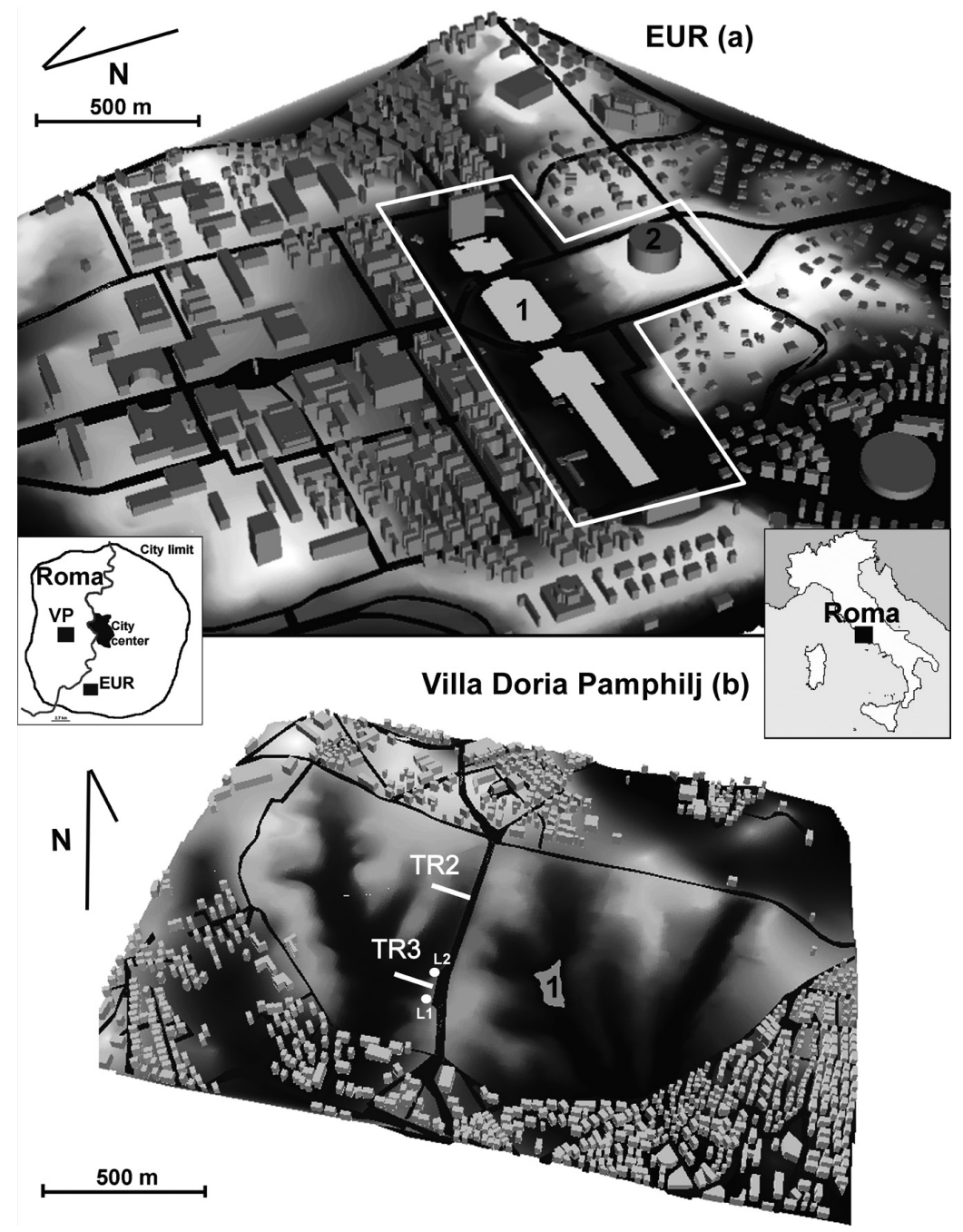

Figure 1: Location of the study areas: the EUR District (a) and Villa Doria Pamphilj (b). Lakes (1) and the Sport Center (2) are positioned in the map. In white the sampled sites.

A "test" site and a "check" site were selected in the city of Rome. The former is the EUR District, which is one of the most polluted areas of the city (Comune di Roma [4]) and it has a dense road pattern (Figure 1). In particular the test site is a relatively large green area, measuring $4 \mathrm{~km}^{2}$, which surrounds an artificial lake (EUR lake), built in 1960. When the road adjacent to this site was built, soils were completely reworked. About 100.000 vehicles pass daily along this 
road. The "check" site, Villa Doria Pamphilj, is a park, created in the $18^{\text {th }}$ century, and it is $2.5 \mathrm{~km}^{2}$ wide and $4 \mathrm{~km}$ far from the city centre. The integrity of this green area was interrupted in 1960, when a big road was built: this road cuts the park in two parts and it is travelled by more than 70,000 cars/day. This second area allowed checking the results obtained in the "test" site. In both test sites, soils are composed of filling materials resulting from the reworking of volcanic rock, belonging to an eruptive volcanic sequence (Salzano [10]).

\section{Sampling}

In both study areas, each sample was composed of three parts collected with a probe, $10 \mathrm{~cm}$ deep in the ground.

In the EUR district, a stratified sampling strategy was carried out and 118 soil samples were collected (Figure 1(a)): the main grid was made of cells of 40 x $40 \mathrm{~m}$, properly oriented to include the entire study area. Sampling sites were randomly selected in a $10 \times 10 \mathrm{~m}$ cells lattice.

Two soil transects were sampled in Villa Doria Pamphilj (Figure 1(b)). Assuming Villa Doria Pamphilj as a single-source site, an oriented sampling strategy was created. Transects, orthogonal to the main road, were sampled in correspondence of different operating conditions of vehicles and were sampled up ( 25 samples) to the distance of $100 \mathrm{~m}$ far from the main road. One is located were cars are accelerated (TR2) and one where vehicles are queued (TR3).

\section{Methods}

All the samples were sieved to obtain soil particles less than $1 \mathrm{~mm}$ and dried out at $105^{\circ} \mathrm{C}$.

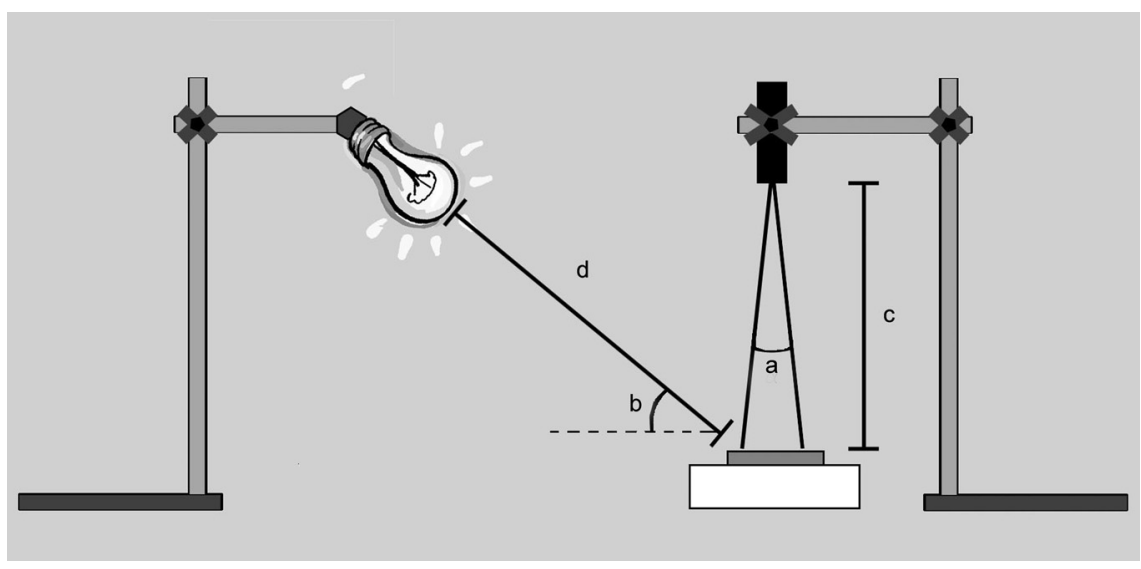

Figure 2: Experimental set up of laboratory reflectance measurements. Notes: (a) Sensor field of view; (b) Light angle of incidence; (c) Optic sensor distance; (d) Light source distance. 


\subsection{Elemental analysis}

Soil sample solutions were prepared by $\mathrm{HF}-\mathrm{HClO}_{4}$ hot digestion. For elemental analysis of $\mathrm{Ca}, \mathrm{Al}, \mathrm{Fe}, \mathrm{Ba}, \mathrm{Zn}$ and $\mathrm{Cu}$ a Perkin-Elmer ICP-OES Optima 2000 was employed. $\mathrm{Pb}$ and $\mathrm{Cd}$ were determined by HGA-AAS, Perkin-Elmer 5100.

\subsection{Radiometry}

Reflectance data were acquired by a field-portable Spectroradiometer (Fieldspec) that measures the reflected solar radiation energy in the wavelength range 350$2500 \mathrm{~nm}$.

The experiment set up is shown in Figure 2. All the analyses were performed in a dark room. Heterogeneities of the sample surface were taken into account by measuring differences obtained varying the position and the orientation of the material. Each sample was measured in 12 different positions and the instrumental error was estimated to be smaller than $3 \%$.

\subsection{Geostatistics}

Distribution maps of each investigated element were obtained applying geostatistical criteria (Armstrong [1]) to the sampled soil dataset. It was necessary to apply a deterministic interpolation method for all the analysed chemical elements because of the complex shape of the study area.

\section{Radiometry}

The experimental dataset, containing all the spectra acquired in sampled soils, shows two major variations. The morphometric study of soil spectra was performed by taking into account three main features: the colour index, calculated as a reflectance integrated between 490 and $700 \mathrm{~nm}$; the slope angle of the spectral curve between 500 and $800 \mathrm{~nm}$; the spectral height, calculated as the mean value of reflectance values between 1520 and $1720 \mathrm{~nm}$. Effects due to grain size are significant in presence of large grain size variations. Sampled soils showed minor variations of the grain size composition. The presence of clays is small and does not justify the changes observed in radiometric spectra.

\subsection{EUR district}

Distribution maps of these indexes were compiled (Figure 3). The soil colour has a "spotted" distribution characterized by the absence of specific trends. The soil spectra height and possibly the signature slope show a distribution affected by their distance from the road. The centre of anomalies observed on these maps are, especially in the case of spectrum height, coherent with those concerning $\mathrm{Pb}$. Lead maps, used as a traffic tracer, can help to compare the radiometric results with the plausible vehicular circulation model.

Results show that areas with lower spectral height indexes and spectral slope indexes are coherent with anomalous lead regions. It is clear how polluted areas can be outlined with this method and how soil radiometric spectra change in correspondence to traffic pollutant sources. More investigations and a larger 
statistical sample are needed to associate these anomalies with a specific chemical contamination.

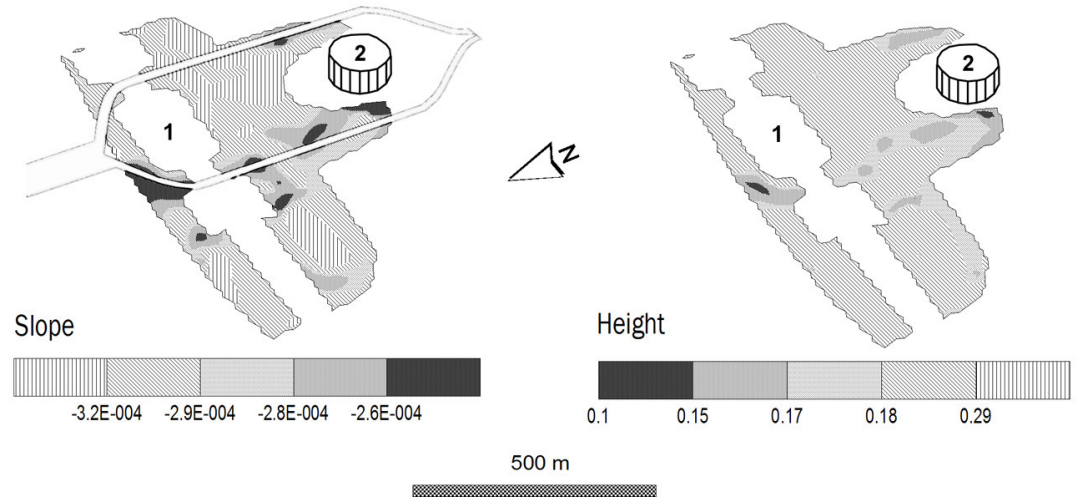

Figure 3: Maps of the distribution of soil spectroradiometric indexes. Eur Lake (1), Sport center (2) and main road are shown.
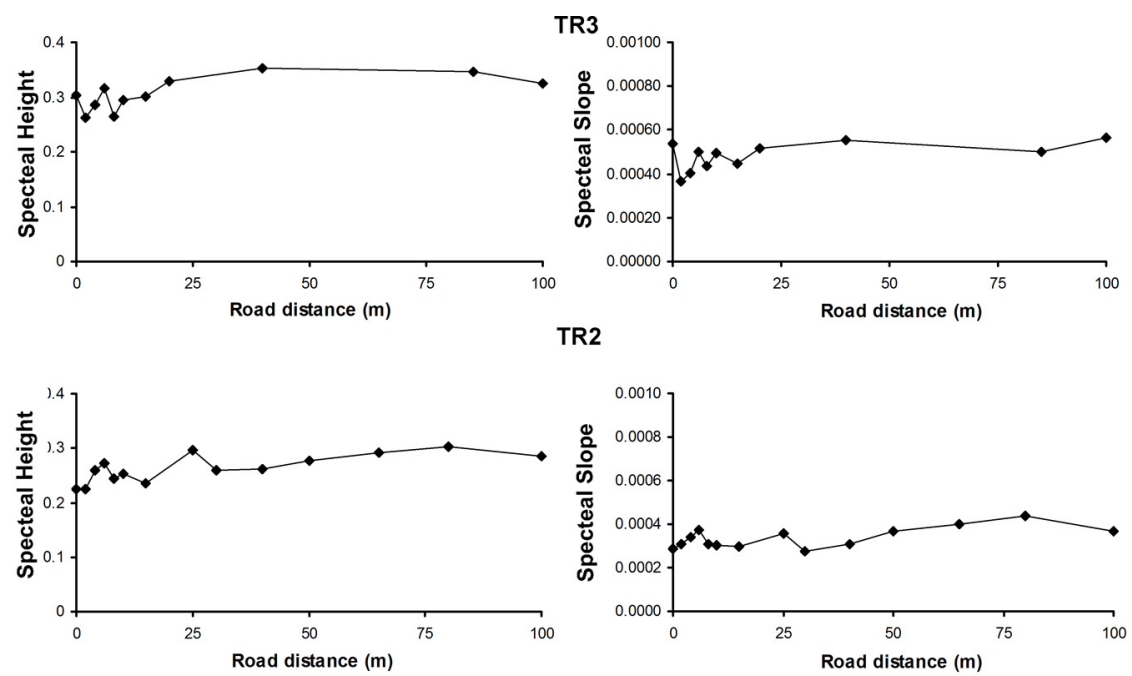

Figure 4: Distribution of spectroradiometric indexes in the soil transects.

\subsection{Villa Doria Pamphilj}

Reflectance values showed high affinities with the $\mathrm{Pb}$ content in most of the investigated interval of wavelength. The proportionality is, also in this case, inverse but it is controlled above all by the road distance. The geometric indexes previously described evidence perfectly this spatial dependence (Figure 4). Radiometric indexes (slope and height) are lower close to the main road and they 
reach the highest values at a distance of more than $30 \mathrm{~m}$ from the road. Trends are evident if we consider that anomalous values are located close to trees and manufacts, that reduce the exposure of soils towards the atmospheric fallout. The comparison between the two soil transects shows that TR2 has lower values of the calculated indexes than TR3.

\section{Soil geochemistry}

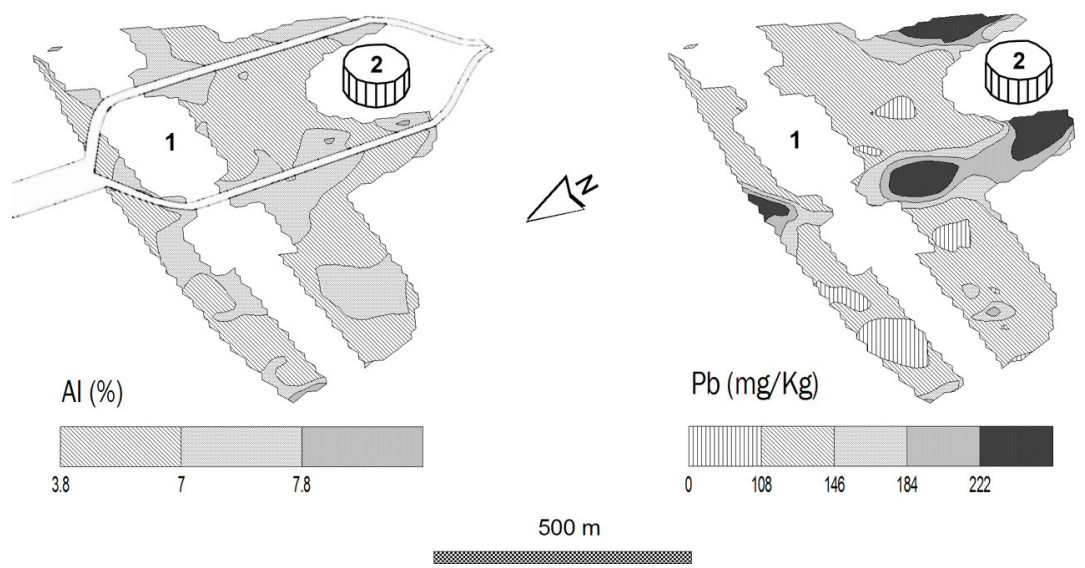

Figure 5: $\quad$ Maps of the distribution of $\mathrm{Al}$ and $\mathrm{Pb}$ as derived from geochemical analysis. Locations of Eur Lake (1), Sport center (2) and of the main road are shown.
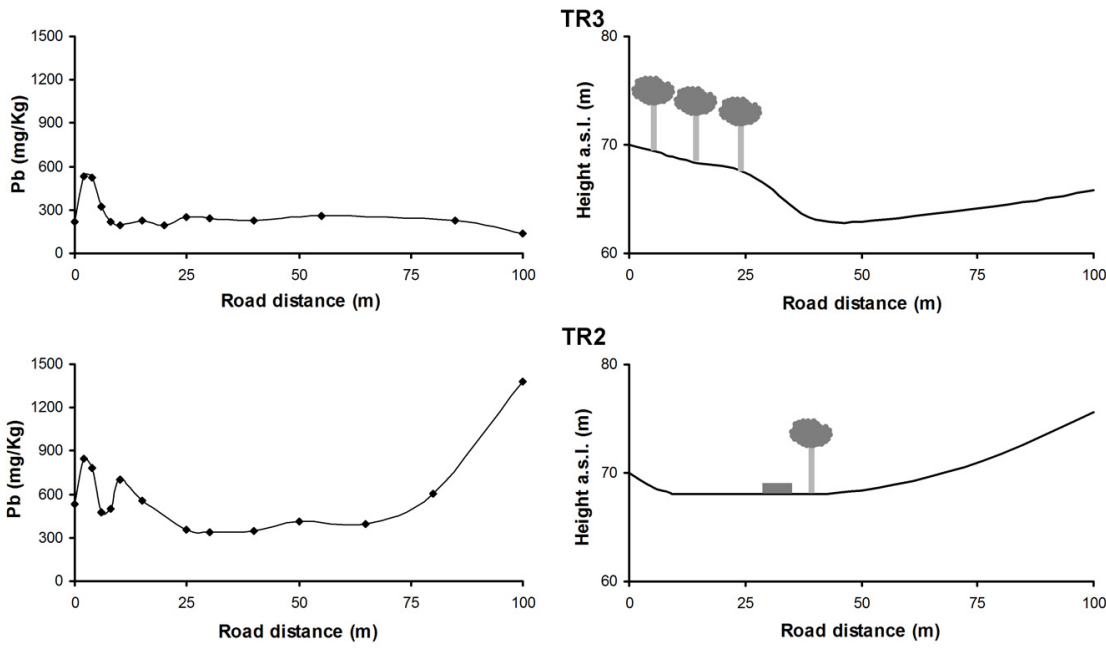

Figure 6: Soil transects TR2 and TR3. The Pb content is on the left while the topography and the presence of vegetation and manufact are on the right. 


\subsection{EUR district}

Table 3 summarizes the chemical analyses performed on soils sampled in this test area. Major elements ( $\mathrm{Al}, \mathrm{Fe}, \mathrm{Ca}$ and $\mathrm{Mn}$ ) show small variations compared to minor metals $(\mathrm{Ba}, \mathrm{Zn}, \mathrm{Cu}, \mathrm{Pb}$ and $\mathrm{Cd})$. An example of the maps concerning the spatial distribution of the chemical elements is shown in Figure 5. The combination of several features (i.e. mineralogy, pedology, vegetation, geology) controls the variation of soil composition and consequently the distribution of each element. Major elements (Al, Fe, Mn and $\mathrm{Ca}$ ) and some heavy metals (Ba, $\mathrm{Zn}, \mathrm{Cu}$ and $\mathrm{Cd}$ ) showed a distribution with values close to the mean within the entire sampled area. Small anomalous areas occur in "confined area". It is reasonable to assume that the high natural concentration of these elements in soils, due to the volcanic nature of the bedrock, makes it difficult to discriminate the concentration related to urban pollution from that of soil natural background. The local anomalies can be explained by the heterogeneity of the soil in the study area, due to the quantity of fills present.

$\mathrm{Pb}$ distribution differs from that of other elements, as it is influenced by the road network. Strong anomalies are located in correspondence of the two carriageways. The highest lead content in soils, that exceeds two or three times the natural background value (about $100 \mathrm{mg} / \mathrm{Kg}$ ), was found close to traffic lights and where a change in road slope occurs. Moreover the anomalous content areas are confined to a strip that is one hundred meters far from the main roads.

\subsection{Villa Doria Pamphilj}

In this confirmation site only lead was analysed, as in the previous case we demonstrated that this element is clearly affected by anthropic emissions and is a good tracer of vehicular emissions. Soil transects TR2 and TR3 differ from each other for their topography and for the presence of vegetation (Figure 6). Traffic conditions represent an additional feature: vehicles moving in proximity of TR2 generally speed up, while reaching the area where TR3 occurs, they slow down. The lead content along the transects generally decreases with increasing distance from the road, except the higher values along transect TR2 (around $1000 \mathrm{mg} / \mathrm{kg}$, found in samples located further from the road, at a distance of 80 and $100 \mathrm{~m}$ ). This anomaly is located on the hill positioned in front of the road and it can be explained as the result of wind blowing that carries the traffic plumes towards the hill. All the discrepancies, showed in the decreasing trend of lead versus the distance from the main road, are located in correspondence of trees, bushes and manufacts, that reduce soil exposure towards atmospheric fallout.

\section{Discussion}

Soil chemistry defines a condition of urban pollution, where $\mathrm{Pb}$ shows significant contamination levels influenced by road pattern. Investigated sites represent two different urban conditions: EUR district has a green area included in a traffic-dense area; Villa Doria Pamphilj is a green area, relatively uncontaminated, which contains and isolates a high-traffic road. 
EUR district permitted investigating the contamination of urban soils in a dense urbanized area, where different roads are present. Maps built using radiometric features (Figures 5 and 6) show a distribution similar to those obtained by a "traditional" geochemical approach (Figures 3 and 4). The spectrum features identify anomalies on the main roads, which can be justified considering traffic in this area, uphill in the western carriageway and downhill in the eastern one (Figure 1(a)). When cars are queued or hold up and do not accelerate, gas pressure is low and particles remain in the exhaust tube, nucleating and growing. When cars accelerate, they emit these dust grains because of the high gas pressure. Driving uphill on the western main carriageway, the exhaust pressure is higher and constant with respect to the opposite sense of direction, where cars travel downhill. The lower spectrum heights and the highest spectrum slope values are located obviously at traffic lights where cars speed up or accelerate to cross the slope. The spectral height and slope maps (Figure 10) differ, probably due to the interference occurring between natural soil heterogeneities and traffic dust fallout (i.e. wind direction, dust content, particulate granulometry).

Villa Doria Pamphilj permitted investigating soils contaminated by a single source and to better comprehend the interaction between soils and radiometry. Coherent conclusions can be carried out with soil transects, which show a decreasing trend of the lead content and increasing trend of spectral indexes with distance from the main road. Some anomalies from these trends were observed and they can be explained noting that index values above the trend are located where vegetation and manufacts are present. This observation is coherent with those evinced from lead trends, that show lower $\mathrm{Pb}$ content in the same locations. Vegetation and manufacts, therefore, mitigate the soil exposure towards atmospheric pollutants and prevent the contamination of soils. The comparison between the two transects confirms that the soil contamination depends on circulating conditions of vehicles. TR2 is located where vehicles are launched at high velocity, while TR3 is positioned where cars are decelerating close to a traffic light.

The "spectral height index" and the "spectral slope index" are features directly relatable to the presence of carbonaceous and/or metallic particles. Low and constant reflectance values, across all the wavelength range, characterize, in fact, spectra of metallic oxides and black carbon (Clark et al. [3]). This atmospheric deposition may also alter the optical properties of soils or may induce a degradation of soil constituents.

Further studies are of course needed for improving the knowledge about the spectroradiometric signature of traffic fallout and about properties changing of soils in response to bad quality of air.

\section{Conclusions}

The geochemical investigation allowed identification of highly polluted soils and to estimate their dependence on vehicular operating conditions. The comparison between radiometric results and geochemical analyses performed on urban soils 
showed that the resulting distribution maps are coherent and influenced by the vehicle operating conditions. Radiometric variations of spectra suggest that the content of traffic dust in urban soils affects the radiometric signature of these materials. As urban particulate matter is composed mainly of black grains, polluted soils tend to adsorb more light than less traffic-exposed soils. These results demonstrate that radiometry has good potentialities for monitoring urban pollution in combination of geochemical analyses.

In conclusion, radiometry allow investigation of urban areas with a detailed spatial resolution at a relatively low cost. The geochemical characterization of anomalous areas is the second step of this approach and it is necessary to quantify soil pollution.

\section{References}

[1] Armstrong, M., Basic linear geostatistics, Springer, Berlin, 1998.

[2] City Majors, Top 100 largest European cities, www.citymajors.com, 2006

[3] Clark, R.N., Swayze, G.A., Gallagher, A.J., King, W.M. \& Calvin, R., The U.S.G.S. Digital Spectral Library Version 1, U.S.G.S. Open File Report 93-592, 1993.

[4] Comune di Roma, Inquinamento dell'aria di Roma, http://www.comune.roma.it, 2003.

[5] Fergusson, D., The heavy elements: chemistry, environmental impact and health effects, Pergamon Press Inc., New York, 1990.

[6] Galvao, L.S., Pizarro, M.A. \& Epiphanio, J.C.N., Variations in reflectance of tropical soils: spectral-chemical composition relationships from AVIRIS data. Remote Sensing of Environment, 75, pp. 245-255, 2001.

[7] Hamilton, R.S. \& Harrison, R.M., Highway pollution, Elsevier, Amsterdam, 1991.

[8] Leone, A.P. \& Sommer, S., Multivariate analysis of laboratory spectra for the assessment of soil development and soil degradation in the Southern Apennines (Italy), Remote Sensing of Environment, 72, pp. 346-359, 2000.

[9] Palacios-Orueta, A. \& Ustin, S.L., Multivariate statistical classification of soil spectra. Remote Sensing of Environment, 57, pp. 108-118, 1996.

[10] Salzano, R., Analisi spaziale e temporale dell'inquinamento da metalli pesanti in ambiente urbano: il caso di Roma. Confronto tra diverse tecniche di monitoraggio, PhD Thesis, Geological Sciences Dept., Roma TRE University, 2005.

[11] Undelhoven, T., Emmerling, C. \& Jarmer, T., Quantitative analysis of soil chemical properties with diffuse reflectance spectrometry and partial least-square regression: A feasibility study, Plant and soil, 251, pp. 319329, 2003. 